Original article

\title{
Paravasal connective tissue parameters vs. morpho-functional indicators in the intraorgan blood vessels of the younger men lungs
}

\author{
Victoria V. Nickel, Vlada P. Efremova \\ Krasnoyarsk State Medical University named after Professor V.F. Voino-Yasenetsky, Krasnoyarsk, Russia
}

Received 4 July 2019, Revised 2 November 2020, Accepted 15 March 2021

(C) 2019, Russian Open Medical Journal

Abstract: Objective - The objective of this research was to identify correlations between the paravasal components connective tissue of the blood vessels of lungs and their morpho-functional parameters.

Material and Methods - In order to determine the structure of the paravasal connective tissue, the histotopographic and histological examination of lung preparations of 20 men corpses of the first mature age period was held, to determine the capacity and capacitive characteristics of the vascular bed, the determination of the Kernogan index (IK) and the veno-arterial index (VAI) were carried out.

Results - It was ascertained that in the structure of the paravasal connective tissue two layers could be conditionally distinguished - the "central" and "peripheral", differing in the architectonics of the fibrous component, the nature of interaction with nearby anatomical structures. It was also revealed that infrared venous vessels IK was expressed in a greater degree in comparison with arterial. When determining VAI vascular, the channel revealed that the area of venous vessels prevailed over the arterial area. Besides, the clear correlation relationships of the structural elements of the paravasal connective tissues were investigated with arterial and venous vessel capacity values and their capacitive characteristics.

Conclusion - The presence of correlation relationships confirmed a clear interaction between structural organization of the paravasal connective tissue and the functional activity of the blood vessels, providing optimal hemodynamic conditions in the organ.

Keywords: paravasal connective tissue, lungs, the first mature age period, intraorgan blood vessels, morpho-functional indicators.

Cite as Nickel VV, Efremova VP. Paravasal connective tissue parameters vs. morpho-functional indicators in the intraorgan blood vessels of the younger men lungs. Russian Open Medical Journal 2021; 10: e0303.

Correspondence to Victoriya V. Nickel. Address: Partizan Zheleznyak Street 1, Krasnoyarsk, 660022, Russia. Phone: +7-913-510-54-89. E-mail: vicanic@mail.ru.

\section{Introduction}

The lungs are the organs that maintain adaptive homeostasis through direct interaction with the external environment. The high rate of gas exchange is facilitated by the architectonics of the intraorgan blood vessels of the lungs, which ensures an even distribution of blood within the small circle of blood circulation. The pulmonary vessels are capable of active tonic activity, despite the fact that the resistance to the blood flow in them is an order of magnitude lower than in the large circle $[1,2]$.

About $10 \%$ of the blood circulating in the human body falls on the small circle vessels, which ensure a high compliance of the pulmonary circulation [3].

According to a number of authors, the components of the hematocirculatory bed are formed in ontogenesis in direct proportion to the load received by the organ and the influence of factors of external regulation of the blood flow - intravascular pressure and extravascular influences $[4,5]$.

The specificity of hemodynamics in the vessels of the pulmonary circulation creates the prerequisites for the morphological features of the blood vessels. Such features are achieved, first of all, due to the structural organization of the connective tissue framework of the vascular wall itself and the surrounding paravasal connective tissue, as well as the features of the morpho-functional parameters of the pulmonary vessels $[6,7]$.

The throughput of blood vessels and the capacitive characteristic of the bloodstream are indicators that reflect the qualitative characteristics of the morphological parameters of the circulatory system. If we take into account that their structure includes connective tissue, then the reliability of these indicators is obvious when studying the paravasal connective tissue at different age periods [8]. At the same time, the determination of the correlation relationship makes it possible to assess the degree of influence of the paravasal connective tissue on the functional capabilities of the organ during the period of biological stability.

In connection with everything stated above, the aim of this study is to identify correlations between the structural elements of the paravasal connective tissue of the intraorganic blood vessels of the pulmonary circulation and their morpho-functional parameters of men aged 21-35 years [9].

\section{Material and Methods}

\section{Organ harvesting and morphological studies}

For the research purpose, lung preparations were taken from 20 corpses of men of the first mature age period (21-35 years old in 
accordance with the classification of age periodization proposed by the Institute of Age Physiology of the USSR Academy of Pedagogical Sciences, adopted at the VII All-Union Congress of Anatomists, Histologists and Embryologists in 1965), who died from violent and non-violent death with a fast rate of dying, with the obligatory condition - death is not associated with diseases of the respiratory system. The organ removal was proceeded not later than 24 hours after the fact of death was confirmed in the course of a standard forensic medical examination on the basis of the corpse examination department of the Krasnoyarsk Regional Bureau of Forensic Medical Examination. In order to determine the staged orientation of the age-related variability of the paravasal connective tissue of the intraorgan blood vessels, histotopograms and histological sections were made with staining according to the standard histological methods: hematoxylin - eosin (an overview method of staining), resorcinol - fuchsin (according to Weigert - to identify elastic fibers), according to Mallory (clear staining of collagen and reticular fibers).

\section{Determination of morpho-functional indicators}

The Kernogan index (IK), which reflects the throughput capacity of arteries and veins, was determined by the ratio of the thickness of the middle layer of the vascular wall (tunica media) to the width of the vessel lumen, multiplied by 100 . The veno-arterial index (VAI), which reflects the capacity of the vessels, was determined by the ratio of the area of the venous and arterial blood vessels of internal organs. To determine the area of arterial and venous vessels, we used two formulas, depending on the shape of the vessel section. To determine the area of a transversely crossed vessel, the following formula was used:

$$
S=\pi m(D-m),
$$

where $m$ is the thickness of the media; $D$ is the diameter of the vessel.

In the case of an ellipsoidal section of the vessel, the formula was used:

$$
S 1=\pi / 4 \times\left(a b-a_{1} b_{1}\right),
$$

where $a$ and $b$ are the long and short diameters of the outer contour of the vessel cut; $a_{1}$ and $b_{1}$ are the diameters of the vessel lumen.

To study the morphology of histological sections, a light microscope was used at a standard magnification of x175 on a hexagonal grating with 25 points.

\section{Statistical analysis}

All obtained data were processed on a personal computer using the MS Office Excel 2007 software package, as well as the Statistica 6.0 and 10.0 for Windows software. Statistical analysis included descriptive statistics methods. Taking into consideration the small sample size $(n=20$ and $n=30)$, nonparametric methods of descriptive statistics were used to determine the median, lower and upper quartiles - Me (LQ, UQ). The Mann-Whitney U-test was used to compare the performance of two study groups. Differences were considered statistically significant at $p<0.05$. In order to study the intensity (weak, medium, strong) of the interdependence between the quantitative parameters of the paravasal connective tissue and the data of the morphofunctional study (IK, VAI), correlation analysis was used. The degree of contingency (intensity) of the features was determined by the pairwise correlation method with the calculation of the coefficient $r$. For the variables $Y$ and $X$, the correlation was considered weak at the modular value $r<0.3$, at $r=0.3-0.69$ the intensity of the connection was considered average, and at $r>0.7$ it was regarded as strong [14].

\section{Results}

As a result of the study, it was found that the structure of the paravasal connective tissue of the lungs includes connective tissue located directly around the adventitia of the blood vessel and closely interacting with it, it can be conditionally called the "central" layer, the width of this zone in the first period of adulthood is $74.59(65.25,85.20) \mu \mathrm{m}$ and paravasal tissue located at a distance, conventionally called the "peripheral" layer, which provides interaction with nearby anatomical structures, its width in the desired age group is $61.60(57.36,64.35) \mu \mathrm{m}$.

In the first mature age period, fibrous elements predominate in the structural organization of the paravasal connective tissue located around the blood vessel, with the corresponding content of the basic substance in the extracellular matrix (Table 1).

The fibers are located loosely, have a mostly annular or arcuate orientation with respect to the lumen of the vessel, in contrast to the outer shell of the vascular wall, which is characterized by concentric and longitudinal orientation of fibrous elements.

The basis of this layer of paravasal connective tissue in this age period are collagen fibers with a thickness of $7.00 \mu \mathrm{m}(6.00,8.00)$ (Table 1). They do not have crimp, which is characteristic of the fibrous structures of the outer shell of the vascular wall.

The number of elastic and reticular fibers in the first mature age period in the structure of the "central" layer of the paravasal connective tissue of the lungs is practically the same (Table 1 ).

The elastic fibers of the paravasal connective tissue are concentrated in the areas peripheral to the vascular wall, they are usually short and, in comparison with collagen and reticular fibers, have crimp. Thin reticular fibers perform a fastening role, interacting widely with the adjacent structures of the adventitia membrane of the vascular wall, being lost in its fibrous stroma.

Table 1. Quantitative characteristics of the paravasal connective tissue of

\begin{tabular}{|c|c|}
\hline & Zone \\
\hline Parameter & "Central" layer \\
\hline \multirow{2}{*}{ Layer width, $\mu \mathrm{m}$} & $74.59(65.25,85.20) \quad 61.60(57.36,64.35)$ \\
\hline & $p<0.001$ \\
\hline \multirow{2}{*}{ Basic substance, \% } & $38.04(36.36,39.05) \quad 30.11(29.35,30.52)$ \\
\hline & $p<0.001$ \\
\hline \multirow{2}{*}{ Total fibers, \% } & $61.97(60.95,63.64) \quad 69.89(69.48,70.65)$ \\
\hline & $p<0.001$ \\
\hline \multirow{2}{*}{ Collagen fibers, $\%$} & $55.82(54.37,58.82) \quad 63.77(63.41,64.43)$ \\
\hline & $p<0.001 \quad \ldots$ \\
\hline \multirow{2}{*}{ Collagen fibers, $\mu \mathrm{m}$} & $13.5(11.50,15.00)$ \\
\hline & $p<0.001$ \\
\hline \multirow{2}{*}{ Elastic fibers, $\%$} & $21.96(21.17,22.78) \quad 23.87(23.37,24.21)$ \\
\hline & $p<0.001$ \\
\hline \multicolumn{2}{|l|}{ Elastic fibers, $\mu \mathrm{m}$} \\
\hline & $22.42(21.22,22.99) \quad 12.34(11.87,12.53)$ \\
\hline $\begin{array}{l}\text { Reticular fibers, } \% \\
.\end{array}$ & $p<0.001$ \\
\hline Reticular fibers, $\mu \mathrm{m}$ & $1.00(1.00,2.00)$ \\
\hline \multirow{2}{*}{ Distance between fibers, $\mu \mathrm{m}$} & $9.00(8.00,9.50)$ \\
\hline & $p<0,001$ \\
\hline
\end{tabular}
intraorgan vessels of the pulmonary circulation $(n=20)$ 
Table 2. Coefficients of correlation between the parameters of the paravasal connective tissue and morphofunctional parameters of the lung vessels $(\mathbf{n}=\mathbf{2 0})$

\begin{tabular}{|c|c|c|c|c|}
\hline \multicolumn{2}{|c|}{ Connective tissue parameters } & \multirow{2}{*}{$\begin{array}{r}R \text { arteries } \\
-0.350\end{array}$} & \multirow{2}{*}{$\begin{array}{r}\text { IR veins } \\
-0.249\end{array}$} & \multirow{2}{*}{$\begin{array}{l}V A I \\
-0.338\end{array}$} \\
\hline \multirow{10}{*}{ "Central" layer } & Fibers, $\%$ & & & \\
\hline & Basic substance,\% & 0.350 & 0.249 & 0.338 \\
\hline & Collagen fibers, $\%$ & -0.071 & 0.478 & 0.287 \\
\hline & Elastic fibers, $\%$ & 0.215 & -0.577 & -0.344 \\
\hline & Reticular fibers, $\%$ & -0.086 & -0.227 & -0.13 \\
\hline & Collagen fibers, $\mu \mathrm{m}$ & 0.155 & -0.032 & -0.28 \\
\hline & Elastic fibers, $\mu \mathrm{m}$ & -0.053 & 0.145 & -0.38 \\
\hline & Reticular fibers, $\mu \mathrm{m}$ & -0.429 & 0.073 & 0.19 \\
\hline & Distance between fibers, $\mu \mathrm{m}$ & 0.217 & 0.197 & 0.19 \\
\hline & Layer width, $\mu \mathrm{m}$ & 0.186 & -0.017 & 0.23 \\
\hline & Fibers, $\%$ & -0.061 & 0.394 & 0.20 \\
\hline \multirow{9}{*}{$\begin{array}{l}\text { "Peripheral" } \\
\text { layer }\end{array}$} & Basic substance,\% & 0.061 & -0.394 & -0.20 \\
\hline & Collagen fibers, $\%$ & -0.196 & 0.342 & 0.32 \\
\hline & Elastic fibers, $\%$ & 0.242 & -0.237 & -0.45 \\
\hline & Reticular fibers, $\%$ & 0.031 & -0.241 & -0.00 \\
\hline & Collagen fibers, $\mu \mathrm{m}$ & -0.179 & -0.398 & 0.05 \\
\hline & Elastic fibers, $\mu \mathrm{m}$ & -0.338 & -0.264 & -0.17 \\
\hline & Reticular fibers, $\mu \mathrm{m}$ & 0.052 & 0.094 & -0.20 \\
\hline & Distance between fibers, $\mu \mathrm{m}$ & 0.087 & 0.021 & 0.00 \\
\hline & Layer width, $\mu \mathrm{m}$ & -0.497 & -0.191 & -0.08 \\
\hline
\end{tabular}

The nature of the relationship between the fibers changes with distance from the vascular wall due to an increase in the distance between them, on average, the distance between the fibers in the structure of the paravasal connective tissue is $4.00(4.00,5.50) \mu \mathrm{m}$.

In the structure of the paravasal connective tissue of the lungs, located at a distance from the blood vessel, in the first mature age period, the fibrous component also prevails, the basis of which, in turn, is made up of collagen fibers in the form of densely completed bundles.

The number of fibrous elements of the extracellular matrix in the paravasal connective tissue located at a distance from the blood vessel increases in comparison with the previous layer to $69.89(69.48,70.65) \%(U=92.0, p=0.019)$, the content of the basic substance, respectively, decreases to 30.11 (29.35, 30.52)\% ( $U=101.0, p=0.020$ ).

In the structure of the extracellular matrix of the "peripheral" layer of the paravasal connective tissue, the number of collagen fibers increases (Table 1), they look like rough, compactly located bundles with a thickness of $13.5(11.5,15.0) \mu \mathrm{m}$ and are characterized by multiple inter-fiber interconnections, forming a dense fine-mesh network.

The thickness of the bundles of collagen fibers in the "peripheral" layer is almost doubled in comparison with the "central" layer. Along with an increase in the size of the fibers, the distance between them increases (Table 1).

The content of elastic fibers in this layer is also somewhat higher than in the layer immediately close to the vessel wall and amounts to $23.87(23.37,24.21) \%(U=227.0, p=0.328)$. The fibers are distributed fairly evenly over the entire width of the layer and anastomosed with each other, forming a kind of reticular structure.

At the same time, the content of reticular fibers in the "peripheral" layer is almost halved (Table 1). Thin reticular fibers are evenly distributed over the entire layer of the paravasal connective tissue and perform a fastening role.

The organization of the fibers in the peripheral sections of the paravasal connective tissue is somewhat different than in the sections close to the blood vessels. Some of the fibers lose their longitudinal orientation, characteristic of the initial sections of the paravasal connective tissue, forming wide interconnections with the underlying connective tissue structures.

When determining the Kernogan index of intraorgan pulmonary vessels, it was found that the throughput of venous vessels is more pronounced in comparison with arteries and is 14.8 $(14.4,15.2)$ and $22.5(19.5,22.9)$, respectively.

When determining the capacitive characteristics of the vascular bed of the lungs, it was found that the area of the venous vessels prevails over the area of arterial, while the veno-arterial index is at the level of $1.6(1.5,1.7)$.

To confirm the direct influence of the structural elements of the paravasal connective tissue on the hemodynamics in the organ and to assess the degree of conjugation of functional indicators (Kernogan index, VAI) with the quantitative content of fibers in the paravasal connective tissue, using correlation analysis, it was found that in the first mature age period, IC arterial vessels of the lungs is characterized by inverse correlations of medium strength with the size of elastic fibers ( $r=-0.338)$ and width $(r=-0.479)$ of the "peripheral" layer of paravasal tissue, as well as with the total fiber content $(r=-0.350)$ and the size of reticular fibers $(r=-0.429)-$ in the "central" layer of the paravasal connective tissue, respectively (Table 2).

IC of venous vessels correlates with the percentage of collagen fibers in both the "central" and "peripheral" layers ( $r=0.342$ and $r=0.478$, respectively), in addition, an inverse relationship of this indicator with the thickness of collagen fibers of the "central" layer $(r=-0.398)$ and with the percentage of elastic fibers in the "peripheral" layer ( $r=-0.577$ ) (Table 2).

For VAl, inverse correlations of average strength in the "central" layer with the total percentage of fibers ( $r=-0.338)$, with the number $(r=-0.344)$ and size $(r=-0.385)$ of elastic fibers were revealed; in the "peripheral" layer, correlations were found only with the number of collagen $(r=0.328)$ and elastic $(r=-0.454)$ fibers (Table 2).

\section{Discussion}

Nowadays, there is no doubt that the features of hemodynamics in various organs are determined not only by the biochemical parameters, but also by the specificity of the biomechanical properties of the vascular wall and perivascular connective tissue, which is confirmed in the publications of a number of authors $[10,11]$

The first mature age period (21-35 years) is defined as the period of biological reliability of connective tissue structures [12]. Having studied the structural organization of the paravasal connective tissue of the vessels of the pulmonary circulation, we found that its zones are characterized by certain qualitative and quantitative specific features of the structural organization depending on the localization, i.e. conventionally distinguished layers differ from each other in width, nature and compactness of the arrangement of fibers, their size.

The study showed that the "central" layer of the paravasal connective tissue of the lungs is in close contact with the outer membrane of the vascular wall, exerting a direct effect on the blood flow in the organ, which is consistent with the known literature data $[13,14]$. As you move away from the blood vessel, the structure of the paravasal connective tissue changes, it is 
defined in the form of rays diverging radially in mutually opposite directions. At the same time, a conical fibrous structure is formed, spreading to different lengths from blood vessels towards the same type of vessels or vessels of a smaller order, which to a certain extent agrees with the works of Wagenseil and Mecham (2012) [15].

Paravasal connective tissue creates specific conditions for hemodynamics in the organ, therefore, one of the most important features is the different width of the "central" and "peripheral" layers, it was found that intraorgan blood vessels of the lungs are characterized by a significantly more developed "central" zone compared to the "peripheral" $(p<0.001)$.

In addition to this, as a result of the study, we have established clear correlations of moderate and strong degrees between almost all parameters of the structural elements of the paravasal connective tissue, with the exception of the sizes of elastic and reticular fibers, with the values of the throughput of arterial and venous vessels of the pulmonary circulation and their capacitive characteristics in the first mature age period.

\section{Conclusion}

The data obtained indicate the presence of correlations between the structural organization of the paravasal connective tissue and the functional activity of the blood vessels of the lungs, which provide optimal hemodynamic conditions, which confirms the clear interaction between the structures of the connective tissue framework of the organ.

\section{Study limitations}

The present study was carried out on preparations of the lungs of corpses of men of the first mature age period who died from violent and non-violent death with a short agonal period, in the absence of pathology of the respiratory system. At the same time, the organs were harvested no later than 24 hours after the death was declared. In this regard, this study is limited only to those conditions that were stated. In addition, the limitations of the study were the identification of the pathology of the studied internal organs during the use of histotopographic and histological techniques.

\section{Conflict of interest}

No conflict of interest is declared.

\section{Ethical approval}

All studies were carried out in compliance with ethical principles (minutes No. 24/2010 of the meeting of the local ethics committee of the Krasnoyarsk State Medical University named after Professor V.F. VoinoYasenetsky, dated May 14, 2010).

\section{References}

1. Evlakhov $\mathrm{VI}$, Poyasov IZ. The physiology of the pulmonary venous vessels. Russian Journal of Physiology 2018; 104(10): 1136-1151. Russian. https://doi.org/10.7868/S0869813918100027.

2. Balko R, Edriss $H$, Nugent $K$, Test V. Pulmonary veno-occlusive disease: An important consideration in patients with pulmonary hypertension. Respir Med 2017; 203-209. https://doi.org/10.1016/j.rmed.2017.10.015.

3. Morozov AA, Movsesyan RR. Hemodynamic aspects of pulmonary and systemic bloodflow in patients with total anomalous pulmonary venous connection. Regional blood circulation and microcirculation 2019; 18(1): 24-30. Russian. https://doi.org/10.24884/1682-66552019-18-1-24-30.
4. Shadrina NKh. On the role of the reaction to the recognition of the flow rate in the regulation of the vascular radius and blood flow. Izvestiya Rossijskoj akademii nauk. Fluid Dynamics 2016; (3): 79-88. Russian. https://doi.org/10.7868/S0568528116030129.

5. Koller A, Toth P. Contribution of flow-dependent vasomotor mechanism to the autoregulation of cerebral blood flow. I Vasc Res 2012; 49(5): 375-389. https://doi.org/10.1159/000338747.

6. Maksimyak LA, Kotlukova NP. Heart connective tissue role in ensuring its structural and functional properties, remodeling caused by pathology in children. Pediatria. Journal named after G.N. Speransky 2016; 95(3): 169-174. Russian. https://elibrary.ru/item.asp?id=26025461.

7. Fomina NV, Fomina MA, Kalinin RE, Suchkov IA. Oxidative carbonylation of vascular wall proteins in dynamics of experimental venous thrombosis. Angiology and vascular surgery 2015; 21(1): 29-34. Russian. https://www.elibrary.ru/item.asp?id=23130461.

8. Skvortsova NV, Koptev VD, Pospelova TI. Morphofunctional changes of peripheral arteries in patients with hodgkin's lymphoma at different stages. Bulletin of the East Siberian Scientific Center SB RAMS 2011; (31(79)): 109-113. Russian. https://www.elibrary.ru/item.asp?id=17295102.

9. Unguryanu TN, Grjibovski AM. Correlation analysis using stata. Human ecology 2014; (9): 60-64. Russian. https://www.elibrary.ru/item.asp?id=21982406.

10. Ranchaeva NA, Yurchuk VA. Hemodynamic features in children with extrahepatic portal hypertension in cavernous transformation of portal vein pre- and postoperatively of porto-systemic shunting. Siberian Medical Review 2014; (5(89)): 63-67. Russian. https://elibrary.ru/item.asp?id=22561255.

11. Cires G, Noll RE Jr, Albuquerque FC Jr, Tonnessen BH, Sternbergh WC 3rd. Endovascular debranching of the aortic arch during thoracic endograft repair. J Vasc Surg 2011; 53(6): 1485-1491. https://doi.org/10.1016/j.jvs.2011.01.053.

12. Balandina IA, Rudin VV, Martirosyan LP. Morphometric parameters of the left atrium according to echocardiographic data in males of the first period of adulthood with the body mass index of 18.5-24.9. Morphology 2018; 153(3): $33 . \quad$ Russian. https://elibrary.ru/item.asp?id=35593179.

13. Pigolkin Yul, Shilova MA, Globa IV. Vascular pathology in the aspect of sudden death in young adults and connective tissue dysplasia: anatomical, physiological, and morphological parallels. Angiology and vascular surgery 2017; 23(1): 36-42. Russian. https://www.elibrary.ru/item.asp?id=28776253.

14. Donina ZhA, Lavrova IN, Baranov VM. Intersystem relationships of respiration and hemodynamics in the initial period of postural effects. Bulletin of Experimental Biology and Medicine 2013; 155(3): 271-274. Russian. https://elibrary.ru/item.asp?id=18909801.

15. Wagenseil JC, Mecham RP. Elastin in large artery stiffness and hypertension. J Cardiovasc Transl Res 2012; 5(3): 264-273. https://doi.org/10.1007/s12265-012-9349-8.

\section{Authors:}

Victoria V. Nickel - MD, DSc, Associate Professor, Department of Human Anatomy and Histology, Krasnoyarsk State Medical University named after Professor V.F. Voino-Yasenetsky, Krasnoyarsk, Russia. https://orcid.org/0000-0003-4923-9592.

Vlada P. Efremova - MD, PhD, Associate Professor of the Department of Human Anatomy and Histology, Krasnoyarsk State Medical University. Professor V.F. Voino-Yasenetsky, Krasnoyarsk, Russia. https://orcid.org/0000-0003-4590-6116. 